\title{
Therapeutic Drug Monitoring by Dried Blood Spot: Progress to Date and Future Directions
}

\author{
Karen Robijns • Remco A. Koster • \\ Daan J. Touw
}

Published online: 14 October 2014

(C) Springer International Publishing Switzerland 2014

\section{Dear Editor,}

We thank Abraham J. Wilhelm and his colleagues for their review article regarding the current progress and future directions of the use of dried blood spot (DBS) in therapeutic drug monitoring (TDM) [1]. Wilhelm et al. discuss the current lack of proficiency testing programs for TDM by DBS and state that the different types of card matrices complicate the design of such a program. The Association for Quality Assessment in Therapeutic Drug Monitoring and Clinical Toxicology (KKGT), a section of the Dutch Foundation for Quality Assessment in Medical Laboratories, acknowledges this lack of proficiency testing for DBS analysis.

The International Organization for Standardization (ISO) state in ISO/IEC 15189:2012 [2] that all medical laboratories are required to participate in interlaboratory comparisons or proficiency testing for quality assessment

\footnotetext{
K. Robijns ( $\square)$. D. J. Touw
}

Association for Quality Assessment in Therapeutic Drug Monitoring and Clinical Toxicology (KKGT), Section of the Dutch Foundation for Quality Assessment in Medical Laboratories (SKML), PO Box 43100, 2504 AC The Hague, The Netherlands

e-mail: k.robijns@ahz.nl

\section{K. Robijns}

Central Hospital Pharmacy, The Hague, The Netherlands

\section{K. Robijns}

CAPHRI School for Public Health and Primary Care,

Maastricht University, Maastricht, The Netherlands

R. A. Koster - D. J. Touw

Department of Clinical Pharmacy and Pharmacology, University Medical Center Groningen, University of Groningen, Groningen, The Netherlands of their analyses. Because there is currently no proficiency testing program for the external quality control of tacrolimus in DBS, the KKGT is planning a pilot. The pilot is expected to start in December 2014 or January 2015.

Interested laboratories are invited to participate in this pilot, and to contact the KKGT (info@kkgt.nl) or the corresponding author. Participation is free of charge because of the experimental nature of the pilot program.

The pilot will include two levels of tacrolimus in DBSs for partial spot analysis. The KKGT will distribute DBSs on various (the most common) types of filter paper, depending on the types of filter paper used by the registered participants.

After the pilot, the participating laboratories will receive a summary of the reported results and further information regarding future rounds for this type of proficiency testing.

\section{References}

1. Wilhelm AJ, den Burger JCG, Swart EL. Therapeutic drug monitoring by dried blood spot: progress to date and future directions. Clin Pharmacokinet. 2014. doi:10.1007/s40262-0140177-7.

2. ISO/IEC 15189:2012. Medical laboratories-requirements for quality and competence. 